\title{
Association between HSV-2 and HIV serostatus in pregnant women of known HIV serostatus attending Mulago Hospital antenatal clinic, Kampala, Uganda
}

\author{
Sarah Nakubulwa ${ }^{1}$, Florence M. Mirembe ${ }^{2}$, Dan K. Kaye ${ }^{2}$ and Deogratias Kaddu-Mulindwa ${ }^{3}$ \\ ${ }^{1}$ Department of Obstetrics and Gynaecology, Mengo Hospital, Kampala Uganda \\ ${ }^{2}$ Department of Obstetrics and Gynaecology, Faculty of Medicine, Makerere University \\ P. O. Box 7072 Kampala, Uganda \\ ${ }^{3}$ Department of Medical Microbiology, Faculty of Medicine, Makerere University, P. O. Box 7072 Kampala, Uganda
}

\begin{abstract}
Background: Studies show that STIs such as HSV-2 increase the probability of HIV-1 acquisition and enhance transmission by increasing susceptibility and infectiousness respectively. The objective of this study was to compare the proportion of HSV-2 in HIV-positive and HIVnegative pregnant mothers attending the antenatal clinic in Mulago Teaching Hospital in Kampala, Uganda.

Methods: This case control study included 50 pregnant women who were HIV positive and 200 controls of pregnant women who were HIV negative and were aware of their serostatus. Data was collected in two parts: the first part involved a pretested interviewer-administered semistructured questionnaire for socio-demographic characteristics, sexual and behavioral history. The second part consisted of a serological test using an ELISA assay specific for IgG against viral glycoprotein G, specific to HSV-2.

Results: The proportion of HSV-2 was 86\% (43/50) among the HIV-positive cases and 62\% (125/200) among the HIV-negative controls. The odds of being HSV-2 seropositive was 3.7 times higher (95\% CI was $1.58-8.61)$ in HIV-positive cases than in the HIV negative controls. The odds of HSV-2 was significantly increased to 5.32 (95 CI was $1.92-14.73$ ) among cases when adjustment was done for age, education, marital status, religion, age at first sexual experience, lifetime partners, type of earning, and whether the mother involved the partner in seeking treatment for sexually transmitted diseases.

Conclusion: The proportion of HSV-2 was higher in HIV-positive cases than in the HIV negative controls.
\end{abstract}

Key words: HSV-2; pregnancy; antenatal care; prevalence; HIV infection

J Infect Dev Ctries 2009; 3(10):803-806.

(Received 29 June 2009 - Accepted 8 September 2009)

Copyright $\odot 2009$ Kaye et al. This is an open-access article distributed under the Creative Commons Attribution License, which permits unrestricted use, distribution, and reproduction in any medium, provided the original work is properly cited.

\section{Introduction}

Herpes simplex virus type 2 (HSV-2) infection is a growing worldwide problem with high prevalence in women in developing countries, especially those with human immunodeficiency virus (HIV) infection[1], where incidence of reactivation is high. In a study in Rakai District in Central Uganda, a prevalence of $69.3 \%$ was found among women 15 to 54 years old [2], while in Tanzania, a prevalence of $39 \%$ was found in the general population [3]. In Cameroon, the seroprevalence of HSV-2 in HIV infected women was $70 \%$ [4], while over $70 \%$ of HIV-infected pregnant women were seropositive for HSV-2 and were more likely to have herpes reactivation in pregnancy and labor [5]. The rate of reactivation in labor was found to be $63.6 \%$ in women of unknown HIV serostatus [6]. Studies show that STIs such as HSV-2 increase the probability of
HIV-1 acquisition and enhance transmission by increasing susceptibility and infectiousness respectively [7]. The prevalence of HIV among pregnant women in Uganda is still high even though it had declined from $30 \%$ in 1992 to $8.7 \%$ by 2000 in some urban areas [8]. The burden of HSV-2 has implications regarding the transmission and infectiousness of HIV-1. Therefore, the effectiveness of any programme to prevent HIV-1 transmission is affected by HSV-2 prevalence. The objective of this study was to compare the seroprevalence of HSV-2 in HIV-positive and HIV-negative pregnant women attending the antenatal clinic in Mulago Hospital. The data generated from this study may initiate improvements to Prevention of Mother-to-Child Transmission (MTCT) programmes that offer anti HSV-2 drugs to all HIV-infected pregnant women 
Table 1. Characteristics of cases (HIV+) and controls (HIV+).

\begin{tabular}{|c|c|c|c|c|}
\hline Variable & $\begin{array}{l}\text { Cases }(\mathrm{HIV}+) \\
\mathrm{N}=\mathbf{5 0}\end{array}$ & $\begin{array}{l}\text { Controls (HIV-) } \\
\mathbf{N}=\mathbf{2 0 0}\end{array}$ & P-value & \\
\hline $\begin{array}{l}\text { Marital status } \\
\text { Single } \\
\text { Married } \\
\end{array}$ & $\begin{array}{ll}24 & (48.0) \\
26 & (52.0) \\
\end{array}$ & $\begin{array}{rr}67 & (33.5) \\
133 & (66.5) \\
\end{array}$ & $<0.001$ & $\begin{array}{l}14.73 ; \\
(4.75-45.70)\end{array}$ \\
\hline $\begin{array}{l}\text { Religion } \\
\text { Muslim } \\
\text { Christian } \\
\end{array}$ & $\begin{array}{ll}22 & (44.0) \\
28 & (56.0) \\
\end{array}$ & $\begin{array}{rr}158 & (79.4) \\
41 & (20.6) \\
\end{array}$ & 0.001 & $\begin{array}{l}0.12 ; \\
(0.03-0.46\end{array}$ \\
\hline $\begin{array}{l}\text { Education level } \\
\text { None/primary } \\
\text { Secondary }\end{array}$ & $\begin{array}{ll}22 & (44.0) \\
28 & (56.0) \\
\end{array}$ & $\begin{array}{rr}72 & (36.2) \\
127 & (63.8) \\
\end{array}$ & 0.042 & $\begin{array}{l}2.92 ; \\
(1.08-7.86\end{array}$ \\
\hline $\begin{array}{l}\text { Type of earning } \\
\text { None } \\
\text { Cash/kind }\end{array}$ & $\begin{array}{ll}36 & (72.0) \\
14 & (28.0) \\
\end{array}$ & $\begin{array}{rr}80 & (40.0) \\
120 & (60.0) \\
\end{array}$ & $<0.001$ & $\begin{array}{l}0.26 \\
(0.13-0.51)\end{array}$ \\
\hline $\begin{array}{l}\text { People involved in seeking } \\
\text { treatment } \\
\text { Others } \\
\text { Self \& partners }\end{array}$ & $\begin{array}{ll}30 & (60.00) \\
20 & (40.0) \\
\end{array}$ & $\begin{array}{rr}77 & (36.0) \\
128 & (64.0) \\
\end{array}$ & $<0.001$ & $\begin{array}{l}3.93 \\
(1.60-9.62)\end{array}$ \\
\hline
\end{tabular}

co-infected with HSV-2. Routine screening for $\mathrm{HSV}-2$ in pregnancy is not done in Uganda.

\section{Materials and Methods}

This case control study was performed at Mulago Hospital Antenatal clinic, Kampala, Uganda. The hypothesis was that pregnant women who are HIV positive have a higher HSV-2 seroprevalence than those women who are HIV negative. The study population was 50 cases and 200 controls sampled from a population of women attending the antenatal clinic in September 2005. The sample size was obtained according to a formula by Schlesselmann [9]. The cases were HIV-positive pregnant women attending Mulago Hospital antenatal clinic, while controls were pregnant HIV negative women. HIV serostatus was determined using rapid test kits and positive tests were confirmed using the ELISA test, while the negative tests were confirmed on the subsequent antenatal visits after ten weeks.

\section{Data collection and management}

An interviewer-administered questionnaire was used to collect data after obtaining informed consent from the study participants. Data was collected on socio-demographic characteristics and sexual and behavioural history. Blood was then drawn aseptically using a needle and syringe, and samples were put in vacutainers from the cubical fossa. The blood samples were taken to the laboratory within 10 minutes and centrifuged after clotting. The serum was then pipetted into cryovials (that were tightly closed) and stored in a freezer at $-20^{\circ} \mathrm{C}$. Serology was done in the Makerere University Medical School, Department of Medical Microbiology Laboratory by two independent laboratory technicians and their results were compared. The serological test utilized the HERPES 2 SELECT ELISA IgG (to glycoprotein G) kit from Focus Technologies, Ca, U.S. The sensitivity of this assay was $96-97 \%$ and the specificity was $98 \%$. This test had purified recombinant type specific IgG-2 antigen immobilized on polystyrene microwells. Once the stored serum samples were diluted, they were incubated in the wells to allow specific antibodies present in the samples to react with the antigen. Nonspecific reactants were removed by washing, and peroxidase conjugated anti human IgG was added and reacted with IgG. Excess conjugate was removed by washing. Enzyme substrate and chromogen were added and the color was allowed to develop. After adding the stop reagent the resultant color was quantified by a spectrometric reading of optical density. Sample optical density readings were then compared with reference-cut off optical density readings to determine results. Indeterminate results were redone with a tiebreaker that was also provided with the kits. Thus all the results given for purposes of this study were either positive or negative. Data analysis was performed using STATA statistical software. 


\section{Results}

As can be seen from Table 1, there were statistically significant differences among the cases and controls in the distribution of education, marital status, religion, type of earning and whether or not the mother involved the partner in seeking treatment for sexually transmitted diseases. The overall proportion of patients with HSV-2 among the women of known HIV serostatus was $67.2 \%$. The seroprevalence of HSV-2 was higher in the HIVpositive cases than in the HIV-negative controls. In the unadjusted analysis, the odds of a positive HSV-2 result were 3.7 (6.14/1.67) times higher among cases compared to controls $(95 \% \mathrm{CI}=1.58-8.61)$. The odds of HSV-2 were significantly increased to 5.32 (95\% CI was 1.92 - 14.73) among cases when adjustment was done for age, education, marital status, religion, age at first sexual experience, lifetime partners, type of earning and whether or not the mother involved the partner in seeking treatment for sexually transmitted diseases.

\section{Discussion}

The proportions of HSV-2 among the HIVpositive and HIV-negative pregnant women $(86 \%$ and $62.5 \%$ ) in Mulago was higher than observed (75\% and 32\%) in a cohort study [5] among 60 HIVinfected pregnant women and 8,408 HIV-negative pregnant women respectively who were delivered at the University of Washington between 1989 and 1995. The overall sero-prevalence in that study [5] was $32.5 \%$ while this study in Mulago showed a much higher figure of $67.2 \%$. This difference may be explained by the risk factors for HSV-2 being more prevalent in our setting than they are in Washington. It may further be explained by the larger proportion of HIV-positive patients in this study. Our results showed a high prevalence of HSV-2 in the controls probably implying that the seroprevalence of HSV-2 in the general population was likely to be higher in our Ugandan setting as well. Since the hospital setting includes sicker people and pregnant women who may be having unprotected sex the higher seroprevalence is not so surprising in our study. In a similar study by Eskild in Norway [10] among pregnant women, the seroprevalence of HSV-2 was $27 \%$ (256/961). The lower rate in Israel and Norway may be due to the fact that the risk factors for HSV-2 may be more prevalent in Uganda. HIV is also more prevalent in our Ugandan setting, with rates of $6.2 \%$ overall and $8.7 \%$ in pregnant women [8]. In Rakai, a rural area of Uganda, among 201 individuals aged 15 to 54years who were selected randomly irrespective of HIV serology, the sero-prevalence for HSV-2 was $69.3 \%$ among the women [2], which is comparable to the overall $67.2 \%$ in this study. The pregnant women in Uganda had a higher seroprevalence probably due to the fact the pregnancy itself reactivates HSV-2 [11]. Physiological changes during pregnancy make the vaginal mucosa thinner and more easily damaged during sexual intercourse than in the non-pregnant vaginal mucosa, thus pregnant women may be more susceptible to HSV-2 [12].

Schacker et al. [13] reported frequent recovery of HIV from HSV-2 lesions. Both prevalent and incident HSV-2 infection have been associated with the risk of HIV acquisition in observational studies [14] and meta-analyses of longitudinal studies [15]. HIV infection further increases risk of HSV shedding and therefore acquisition from infected partners [16]. HSV-2 reactivation is associated with increased HIV viral load, both in genital secretions and in plasma. Such HSV-2 infection is associated with significantly higher amounts of HIV-1 in plasma and in genital secretions in women with sexually acquired HIV-1 [17], which seems to have clinical implications suggesting that HIV-1 replication can be reduced with antiviral therapy directed at HSV-2. However, randomized clinical trials on suppression of HSV-2, especially the associated genital ulcers, was not found to reduce risk of HIV acquisition in HSV-2 infected persons [18], nor did they reduce HIV transmission in persons infected with both HIV and HSV-2. There is therefore a complex relationship between HSV-2 and HIV infection [19].

Since the participants were outpatients and most were seen on their first visit to the clinic, it is unlikely that their results could have been due to iatrogenic infection from prior use of contaminated equipment. HSV-2, HIV and other sexually transmitted infections may be acquired as nosocomial or iatrogenic infections in settings where there is use of unhygienic invasive procedures involving use of unsterilized or poorly sterilized instruments.

In conclusion, since the seroprevalance of HSV-2 in this study was 3.7 times higher in HIV-positive cases than in HIV-negative controls, we suggest that HSV-2 is a risk factor for HIV infection. 


\section{Acknowledgements}

This study was financed by the German Academic Exchange Programme (DAAD = Deutsch Akademische Austausch Deinst). We are indebted to all the women who participated in the study, without whose consent this research would not have been possible.

\section{References}

1. Sande AM, Voibetbing PA (Eds) The Medical Management of AIDS, $6^{\text {th }}$ Edition. 1999. pages 6, 438-446, 546-547 and 565-566.

2. Emonyi IW, Gray RH, Zenilman J. Schnidt K, Sewankambo KN, Serwadda D Kiwanuka N, Nalugoda F (2000) Seroprevalence of HSV 2 in Rakai district, Uganda. East Afr Med J 77: 428-30.

3. Msuya SE, Hussein A, Sam NE, Jeansons, Stray PB (2003) Seroprevalence and correlates of HSV 2 among urban Tanzanian woman. Sexually Transmitted Diseases 30: 58892.

4. Eis-Hubinger AM, Yankee, Bitoungui DM, Ndjomou J. Prevalence of HSV-2 in Cameroon in Doula. www.pubmed.com. Accessed Feb 2004.

5. Hitti J, Watts DH, Burchett SK (1997) Herpes simplex virus seropositivity and reactivation at delivery among pregnant women infected with human immuno-deficiency virus. Am Journal Obstetric Gynecology 177: 450.

6. Brown Z, Wald A, Morrow R, et al. (2003) Effect of serological status and caesarian delivery on transmission rates of HSV from mother to infant. JAMA 289: 203-209.

7. Serwadda D, Gray RH, Sewankambo NK, WabwireMangen F, Chen et al. (2003) HIV acquisition associated with genital ulcer disease and HSV 2 infection: a nested case-control study in Rakai, Uganda. J Infect Dis 188: 1492-7.

8. Uganda Ministry of Health (MOH) STD/ACP (AIDS control programme) Ministry Report 2001.

9. Schesselmann J. Case-control study design, conduct and analysis 1982; (6): 145-157. Oxford University Press.

10. Eskild A, Jeansson S, Jenum PA (1999) Antibodies against HSV-2 among pregnant women in Norway. Norwegian Tidsskrift for Den Norske Laegeforening 119: 2323-6.

11. Dan M, Glezerman M, Raveh D. Samra Z (2003) Prevalence and risk factors for HSV-2 among pregnant women in Israel. Sex Transm Dis 30: 835-8.
12. Greenwood D, Slock R, Peutheter J (Eds) A guide to Microbial infections. $15^{\text {th }}$ Edition. 1997. Longman Asia, pp 403-409.

13. Schacker T, Ryncarz AJ, Goddard J, Diem K, Shaughnessy M, Corey L (1998) Frequent recovery of HIV-1 from genital herpes simplex virus lesions in HIV-1 infected men. JAMA 280: 61-66.

14. Stamm WE, Handsfield HH, Rompalo AM, Ashley RL, Roberts PL, Corey L (1988) The association between genital ulcer disease with acquisition of HIV infection in homosexual men. JAMA 260: 1429-1433.

15. Freeman EE, Weiss HA, Glynn JR, Cross PL, Whitworth JA, Hayes RJ (2006) Herpes simplex virus 2 infection increases HIV acquisition in men and women: systematic review and meta-analysis of longitudinal studies. AIDS 20: 73-83.

16. Augenbraun M, Feldman J. Charging K, et al. (1995) Increased genital shedding of HSV-2 in HIV seropositive women. Ann Intern Med 123: 845.

17. Nagot N, Ouedraogo A, Foulongne V, et al. (2007) Reduction of HIV-1 RNA levels with therapy to suppress herpes simplex virus. N Engl J Med 356: 790-799.

18. Celum C, Wald A, Hughes J et al. (2008) Effect of aciclovir on HIV-1 acquisition in herpes simplex virus 2 seropositive women and men who have sex with men: a randomised, double-blind, placebo-controlled trial. Lancet 371: 2109-19.

19. Corey L, Wald A, Celum CL, Quinn TC (2004) The effects of herpes simplex virus-2 on HIV-1 acquisition and transmission: a review of two overlapping epidemics. J Acquir Immune Defic Syndr 35: 435-445.

\section{Corresponding Author}

Dan K. Kaye

Obstetrics and Gynecology Department

Makerere University Medical School

PO Box 7072, Kampala

Uganda

Tel 256-414-534361

Fax 256-414-533451

Email: dankkaye@yahoo.com

Conflict of Interest: No conflict of interest is declared. 